\title{
Chemotactic Response of Dictyostelium discoideum Cell to C-AMP at the Culmination Stage
}

\author{
Masanobu Kitami \\ Department of Physics, Faculty of Education, Yokohama National University, \\ Tokiwadai 156, Hodogaya-ku, Yokohama, 240 Japan
}

Received January 27, 1983

The morphogenetic movement of $D$. discoideum cells is usually expressed as the unified collective motions characterized as aggregation, migration and culmination. At the end of the pseudoplasmodial stage, the cell mass (pseudoplasmodium) stops its migration and moves vertically in preparation for the final differentiation which results in the formation of the fruiting body. This movement of cells in the culminating fruiting body is likened to a "fountain running backward" process (Bonner 1967, Loomis 1975). In this process, the culminating mass of cells seems to be lifted up along the rising stalk by accepting or producing some type of force (Kitami, in preparation).

It is well known that the aggregation-competent cells are attracted to adenosine 3', 5'-cyclic monophosphate (c-AMP) (e.g., Konijn et al. 1967). Recently, it has also been proposed that cell movement at the pseudoplasmodial stage might be principally controlled by c-AMP (Maeda 1977). On the contrary, as far the control system for the cell movement in the culminating fruiting body, some mathematical (Zeeman 1977, Rubinow et al. 1981) and hypothetical (Sussman and Schindler, 1978) models, in which some chemotactic agent like c-AMP is supposed, have been proposed; however, any tangible evidence for the cell movement during the culmination stage to support these models has not yet been available.

Therefore, in order to discuss the propriety of such models as described above, at first, it is necessary to define the correlation between the cell movement and the chemo-attractant controlling cell movement during the culmination stage.

So, in the present study, the author will show some demonstrations in which the cell movement during the culmination stage, too, may be principally controlled by c-AMP. Moreover, on both pseudoplasmodium cells and fruiting body cells, the dependence of the changes in the motility of these cells upon the varying concentrations of c-AMP, that had not previously been available, are also presented.

\section{Materials and methods}

D. discoideum strain NC4 was incubated at $25^{\circ} \mathrm{C}$ with Klebsiella aerogenes on the nutrient agar (Bonner 1947). When the amoebae had aggregated to form the lumps preceding the "finger" stage, they were transferred separately onto the surface of the nonnutrient agar $(2 \% \mathrm{w} / \mathrm{v})$ maintained at $25^{\circ} \mathrm{C}$.

i) The test cells: Several hours after, when each of the transferred lumps 
had transformed into the culminating fruiting body in the dark, the cell mass, which is lifted up along the rising stalk of that fruiting body, was dissociated from the stalk. The dissociated cell mass consisted of both prestalk cells and prespore cells, except for the tip cells, of the culminating fruiting body. The tip cells were excluded from the test cells so as not to disturb the field of the test cells, because it is generally believed that the tip cells could become a pacemaker in the cell movement during the stages following the aggregagtion stage.

ii) The Sources of Stimulus: A) One source was an intact culminating fruiting body. B) The others were four kinds of $1.5 \%$ agar blocks containing c-AMP ( $1 \times$ $10^{-4} \mathrm{M}, 1 \times 10^{-5} \mathrm{M}, 5 \times 10^{-6} \mathrm{M}$ and $\left.1 \times 10^{-6} \mathrm{M}\right)$.

iii) The Ca-Mg agar plate: A $2 \%$ agar containing $25 \mathrm{mM} \mathrm{CaCl}_{2}$ and $25 \mathrm{mM}$ $\mathrm{MgCl}_{2}$ was prepared to make the formation of cell stream enhanced (Maeda 1977).

Test (I): The test cells were evenly spread in the form of a disk over the Ca$\mathrm{Mg}$ agar plate. At the same time, an intact culminating fruiting body was laid down on its side on a field of the test cells. They were incubated at $25^{\circ} \mathrm{C}$ in the dark; then the movement of the test cells was photographed by a photomicrograph at intervals of $5 \mathrm{~min}$ over a period of $60 \mathrm{~min}$.

Test (II): The test cells were evenly spread in a line over the Ca-Mg agar plate. At the same time, the c-AMP source (a $1.5 \%$ agar block) was placed at a moderate distance from the edge of the line of the test cells. They were incubated at $25^{\circ} \mathrm{C}$ in the dark; then the movement of cells toward the agar block containing c-AMP was photographed by a photomicrograph at intervals of 5 min over a period of $60 \mathrm{~min}$.

Test (III): The index of the motility (I.M.) of the test cells attracted to the c-AMP source at the culmination stage was estimated. The test cells were evenly spread in a line at a distance of $2.5 \mathrm{~mm}$ from the edge of the c-AMP source (a $1.5 \%$ agar block) on the Ca-Mg agar plate and incubated at $25^{\circ} \mathrm{C}$ in the dark. Then, at intervals of $2 \mathrm{~h}$ over a period of $12 \mathrm{~h}$, the migration of the test cells toward the c-AMP source was photographed on $35 \mathrm{~mm}$ film together with a rule by a photomicrograph. Both the extent of the area occupied by the test cells attracted to the c-AMP source for $12 \mathrm{~h}(\mathrm{~S})$ and the length of a line formed by the spread cells at the starting time (L) were measured by projecting the photographs on a screen (Fig. $2 B$ ). By such procedures, twelve runs or so were made for each measurement carried out under four kinds of c-AMP conditions $\left(1 \times 10^{-4} \mathrm{M}\right.$ through $\left.1 \times 10^{-6} \mathrm{M}\right)$. The index of motility (I.M.) was defined as $S / L$ in order to normalize the degree of the migration of the test cells throughout all the measurements. So, the movement of the test cells in each measurement was quantitatively represented as a rectilineal extension of migration in the direction of the c-AMP source, and was directly compared with each other. The value $(\langle\mathrm{I} . \mathrm{M}\rangle$.$) shown in the ordinate of Fig.$ 3 indicates the arithmetic mean of the (I.M.) values in all runs carried out under each c-AMP condition.

Test (IV): The index of the motility (I.M.) of the cells, except for the tip cells, dissociated from the migrating pseudoplasmodium at the pseudoplasmodial stage, was also estimated, to compare with that at the culmination stage by using the same methods as Test (III). 
Results and discussion

When an intact culminating fruiting body was laid down on its side on the field of the test cells, the test cells, forming cell streams, began to move toward the culminating mass of cells of that fruiting body in about $30 \mathrm{~min}$ (Fig. 1A). This was just like the usual aggregation pattern observed at the aggregation stage, where the aggregation-competent cells, forming cell streams, move in order toward the aggregation center. It was, however, different from the cell movement at the pseudoplasmodial stage, where more cell streams were formed toward the tip region of the pseudoplasmodium in particular (Maeda 1977); so the entire culminating mass of cells was likely to be equally competent as the source of stimulus. This point of difference must be clarified by more detailed studies. The following can be suggested from the results of Test (I). (a) Some chemo-attractant, which controls the cell movement, is present in the culminating fruiting body as well as in the aggregation center. (b) Cells at the culmination stage, too, are chemotactically sensitive to this chemoattractant.

Based on the results of Test (I), Test (II) was designed to test whether this chemoattractant is c-AMP as in other stages. Similar to the results in Test (I), the test cells began to migrate toward the agar block containing c-AMP $\left(5 \times 10^{-6} \mathrm{M}\right)$ in about $30 \mathrm{~min}$ when they were placed at a moderate distance apart from the agar block (Fig. 1B). Almost all of the test cells had gathered at the edge of the agar block when the test was carried on longer. On the other hand, the test cells dissociated from the mature fruiting body (i.e., the "tip" of it had been disappeared) were not senitive to c-AMP at all. The results of Test (II) show that (c) the chemo-attractant taking part in the cell movement during the culmination stage is also c-AMP, as was expected.

The motive forces of the migrating pseudoplasmodium (Kitami 1982) and of the culminating fruiting body (Kitami, in preparation) have been estimated in recent studies in order to analize the unified collective motion of D. discoideum cells. Existence of some common mechanism between these two collective motions may be suggested, since the order of magnitude of the estimated values for the two was almost equal. Here, the results in the present study described above show a tangible evidence that the cell movement in the culminating fruiting body is, at least, principally controlled by c-AMP as well as the cell movement at the aggregation and the pseudoplasmodial stages (results (a) through (c)). In other words, it becomes clear that a common mechanism, operating through the chemotactic response of the cells to the c-AMP upon their movement, exists in all the collective motions (aggregation, migration and culmination) of $D$. discoideum cells.

In Test (III), the dependence of the changes in the cell motility at the culmination

Fig. 1. Photomicrographs show that the fruiting body cells are chemotactically attracted to two kinds of c-AMP sources on $2 \% \mathrm{Ca}-\mathrm{Mg}$ agar plate, forming cell streams $(\times 60)$. A, an intact culminating fruiting body was laid down on its side as a c-AMP source on a field of the test cells dissociated from fruiting body. Suffixes (f.b.) and (st) indicate the culminating mass of cells and the stalk of that fruiting body, respectively. B, a $1.5 \%$ agar block containing c-AMP $\left(5 \times 10^{-8} \mathrm{M}\right)$ was placed at a moderate distance from the edge of the fruiting body cells spread in a line. They were incubated for $60 \mathrm{~min}$ at $25^{\circ} \mathrm{C}$ in the dark. 


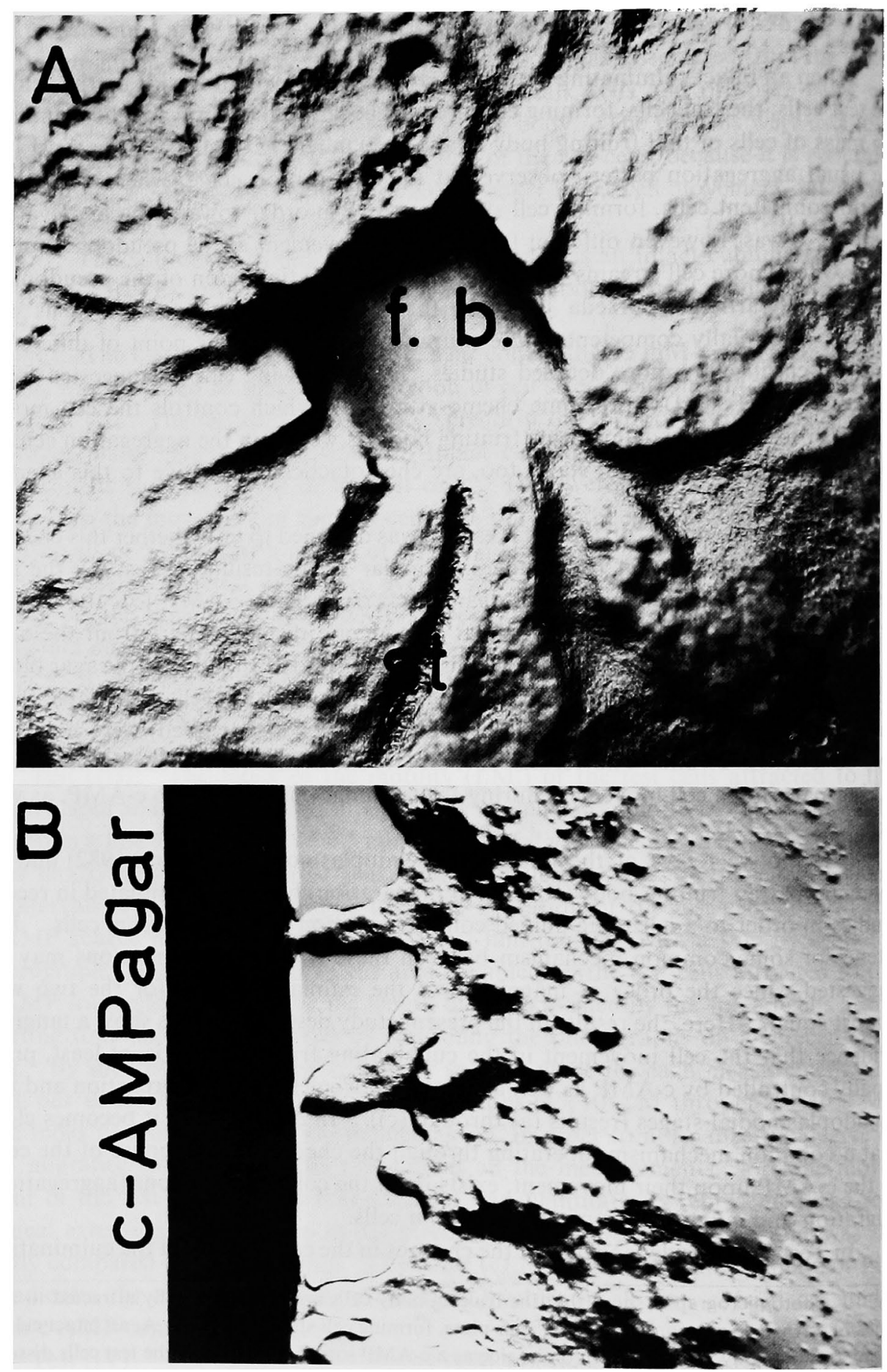


stage upon the varying concentrations of c-AMP was investigated, and the results were compared with those obtained at the pseudoplasmodial stage by the same

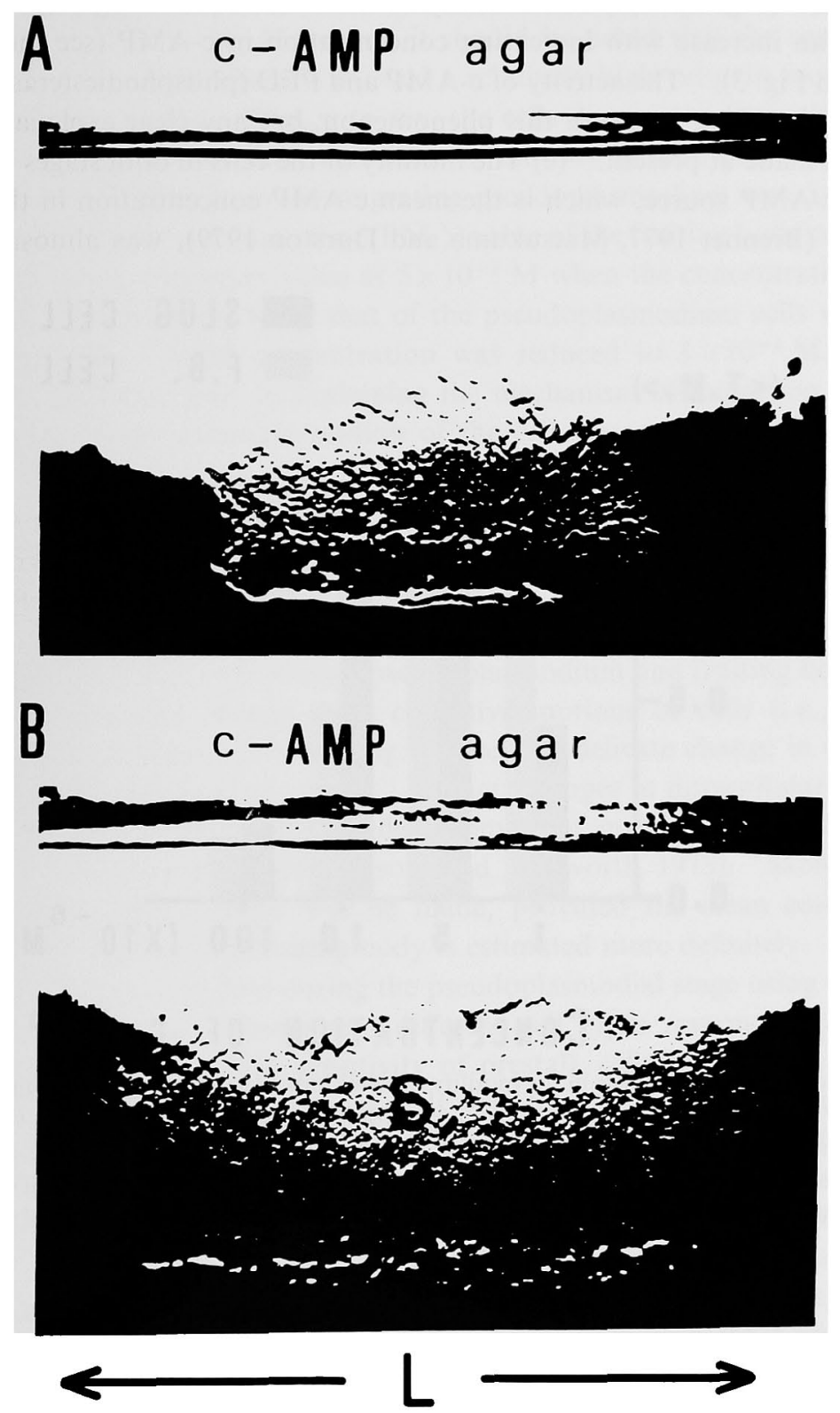

Fig. 2. Photographs showing the chemotactic response of the test cells to c-AMP source on $2 \%$ Ca-Mg agar plate $(\times 20)$. A, a $1.5 \%$ agar block containing c-AMP was placed at a distance of 2.5 $\mathrm{mm}$ from:the edge of the test cells spread in a line. They were incubated for $12 \mathrm{~h}$ at $25^{\circ} \mathrm{C}$ in the dark. B, suffixes (S) and (L) to estimate the index of cell motility (I.M.) are also shown in this figure.

methods (Test (IV) (Fig. 2A, B). By defining the index of motility (〈I.M. $\rangle$ ), the chemotactic sensitivity of the cells to c-AMP in both stages could be compared with 
each other quantitatively in terms of the difference in motility of them. The comparison showed that their sensitivity depended upon the changes in the concentration of c-AMP (Fig. 3). (d) The motility of the cells in both stages did not necessarily show an increase with increasing concentration in c-AMP (see the values at $1 \times 10^{-4} \mathrm{M}$ in Fig. 3). The activity of c-AMP and PED (phosphodiesterase) secreted from the cell itself may concern this phenomenon, but any clear explanation about it can not be made at present. (e) The motility of the cells in both stages toward the $5 \times 10^{-6} \mathrm{M}$ c-AMP source, which is the mean c-AMP concentration in the pseudoplasmodium (Brenner 1977, Matsukuma and Durston 1979), was almost the same

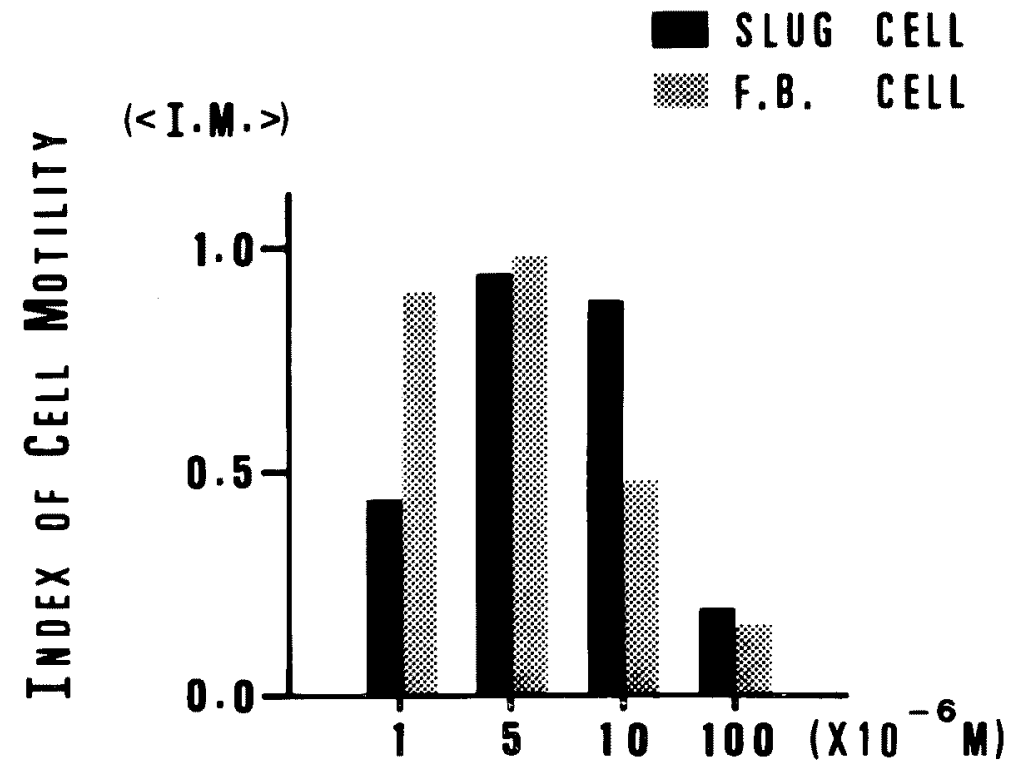

CONCEMtRation of C-AMP

Fig. 3. Dependence of the changes in the motility of two kinds of cells upon the varying concentra-

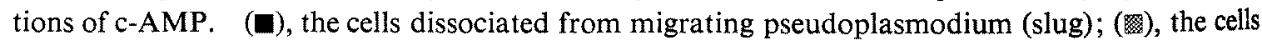
from culminating fruiting body (F.B.). The abscissa indicates the concentration of c-AMP in the agar block attracting these cells, and the ordinate shows the mean value of the index of cell motility (〈I.M. $\rangle$ ). These mean values are arithmetically calculated from the (I.M.) values in all runs carried out under each c-AMP concentration.

and was also the highest $(\langle\mathrm{I} . \mathrm{M}\rangle=.0.9-1.0)$. This value in $(\langle\mathrm{I} . \mathrm{M}\rangle$.$) was converted$ to the velocity of cell movement as ca. $0.4-0.5 \mathrm{~mm} / \mathrm{h}$, which was almost comparable to the mean velocity of the cells in the cell streams at the aggregation stage (Bonner 1967 and Maeda 1978). A relay system, in which the c-AMP signal is propagated from cell to cell, is considered to be in operation in the cell movement in the cell streams at the aggregation stage (e.g., Gerisch et al. 1977). This agreement among the velocities of the cell movement in the cell streams formed at different stages suggests a possibility that the cells at the culmination stage, too, latently possess an ability to operate such a relay system as the cells do at the aggregation stage. There are some indirect evidences in favor of this suggestion. The cells during the pseudo- 
plasmodial stage behave with the periodic movement which is characteristic of the cell movement during the aggregation stage (Durston and Vork 1979), and also the movement of the culminating mass of cells of fruiting body seems to be periodic (Yamada et al. 1981). (f) Moreover, it should be noted that the range of c-AMP concentration, in which the cells showed a relatively high value in motility, was different in the two stages. That is to say, the cells dissociated from the culminating fruiting body kept a relatively high value of motility in the range of $1-5 \times 10^{-6} \mathrm{M}$, while those dissociated form the migrating pseudoplasmodium was $5 \times 10^{-6} \mathrm{M}-1 \times$ $10^{-5} \mathrm{M}$. Conversely speaking, the $(\langle\mathrm{I} . \mathrm{M}\rangle$.$) value of the fruiting body cells was decre-$ ased to half of its maximum value at $5 \times 10^{-6} \mathrm{M}$ when the concentration of c-AMP was raised to $1 \times 10^{-5} \mathrm{M}$, while that of the pseudoplasmodium cells was decreased to half when the c-AMP concentration was reduced to $1 \times 10^{-6} \mathrm{M}$. This result may be an important part in explaining the mechanism of migration and culmination in terms of the collective motion of the cell mass mediated by c-AMP sensitivity.

Considering from these results described above ((d) through (f)), it may be assumed that the two modes of collective motion of $D$. discoideum cells, the migration and the culmination, are basically controlled by the similar c-AMP control system to that in the aggregation; however, the motility of the cells that move actually in the cell aggregates (i.e., cell stream, pseudoplasmodium and fruiting body) has some difference in quantity among these collective motions of cells (i.e., aggregation, migration and culmination) according to a certain delicate change in concentration of c-AMP within this control system. In fact, changes in intracellular and extracellular c-AMP concentrations during development of myxamoebae of $D$. discoideum Ax-2 have been reported (Malkinson and Ashworth 1973). More detailed researches about this problem will be made, provided the mean concentration of c-AMP in the culminating fruiting body is estimated more definitely.

Qualitative observations during the pseudoplasmodial stage using the cinematographical methods have shown that different cell types responded to different cAMP concentration (i.e., the sensitivity of prestalk cells was high in high c-AMP concentration and that of prespore cells was high in low c-AMP concentration) (Matsukuma and Durston 1979, Durston and Vork 1979). Motive force per unit volume of an anterior isolate (prestalk cell rich) of a pseudoplasmodium was much larger than that of a posterior isolate (prespore cell rich) (Inouye and Takeuchi 1980). The motive force of the culminating mass of cells of fruiting body was about 0.5 times as large as that of the migrating pseudoplasmodium (i.e., the values of culminating fruiting body and migrating pseudoplasmodium were $0.8 \times 10^{5} \mathrm{dyn} / \mathrm{cm}^{3}$ and $1.5 \times 10^{5} \mathrm{dyn} / \mathrm{cm}^{3}$, respectively) (Kitami 1982, Kitami in preparation). In connection with these reports, it is suggested that such difference in cell motility as described in result (f) may be caused by the changes in their activities to c-AMP according to develop their differentiation into two cell types (i.e., stalk cells or spore cells).

Some phenomena which seem to support this assumption were also observed in Test (III). The c-AMP sensitivity of the cells in the culmination stage was found to be much higher in prespore cells than in prestalk cells. So, more detailed studies were carried out by separating the test cells in each stage into prestalk and prespore 
cells. The data are now under analysis to be reported soon.

\section{Summary}

A certain chemo-attractant which controls the cell movement is present in the culminating fruiting body as it is in the aggregation center. Cells at the culmination stage, too, are chemotactically sensitive to c-AMP. The motility of the fruiting body cells depends upon the changes in c-AMP concentration; moreover, it tends to be high in lower c-AMP concentrations as compared with that of the pseudoplasmodium cells. This suggests that the cell movement may be basically controlled by c-AMP in the culminating fruiting body as well as in the aggregating cell streams and the migrating pseudoplasmodium.

\section{References}

Bonner, J. T. 1947. Evidence for the formation of cell aggregates by chemotaxis in the development of the slime mold $D$. discoideum. J. Exp. Zool. 106: 1-26.

— (ed.) 1967. The Cellular Slime Mold, 2nd ed., Princeton Univ. Press, Princeton, New Jersey.

Brenner, M. 1977. Cyclic AMP gradient in migrating pseudoplasmodia of the cellular slime mould Dictyostelium discoideum. J. Biol. Chem. 252: 4073-4077.

Durston, A. J. and Vork, F. 1979. A cinematographical study of the development of vitally stained Dictyostelium discoideum. J. Cell Sci. 36: 261-279.

Gerisch, G., Maeda, Y., Malchow, D., Roos, W. and Wurster, B. 1977. in Development and Differentiation in the Cellular Slime Moulds (eds. Cappuccinelli, P. and Ashworth J. M.), pp. 105-124. Elsevier/North-Holland Biomedical Press, Amsterdam-New York.

Inouye, K. and Takeuchi, I. 1980. Motive force of the migrating pseudoplasmodium of the cellular slime mould Dictyostelium discoideum. J. Cell Sci. 41: 53-64.

Kitami, M. 1982. The motive force of the migrating pseudoplasmodium of Dictyostelium discoideum under dark and light conditions. J. Cell Sci. 56: 131-140.

Konijn, T. M., Van de Meene, J. G. C., Bonner, J. T. and Barkley, D. S. 1967. The acrasin activity of adenosine-3', 5'-cyclic phosphate. Proc. Natl. Acad. Sci. U.S.A. 58: 1152-1154.

Loomis, W.F. (ed.) 1975. Dictyostelium discoideum: A Developmental System. New York: Academic Press.

Maeda, Y. 1977. Role of cyclic AMP in the polarized movement of the migrating pseudoplasmodium of Dictyostelium discoideum. Develop. Growth and Differ. 19: 201-205.

Maeda, M. and Maeda, Y. (eds.) 1978. The Biology of Slime Moulds. UP Biology Tokyo Univ. Press. (in Japanese).

Malkinson, A. M. and Ashworth, J. M. 1973. Adenosine 3', 5'-cyclic monophosphate concentrations and phosphodiesterase activities during axenic growth and differentiation of the. cellular slime mould Dictyostelium discoideum. Biochem. J. 134: 311-319.

Matsukuma, S. and Durston, A. J. 1979. Chemotactic cell sorting in Dictyostelium discoideum. J. Embryol. Exp. Morph. 50: 243-251.

Rubinow, S. I., Segel, L. A. and Ebel, W. 1981. A mathematical framework for the study of morphogenetic development in the slime mold. J. Theor. Biol. 91: 99-113.

Sussman, M. and Schindler, J. 1978. Models and hypotheses: A possible mechanism of morphogenetic regulation in Dictyostelium discoideum. Differentiation 10: 1-5.

Yamada, T., Ishii, K. and Higuchi, G. 1981. Proceedings of the 46th Anual Meeting of the Botanical Society of Japan 46: 129. (in Japanese).

Zeeman, E. C. (ed.) 1977. Catastrophe Theory; Selected Papers, 1972-1977. London: AddisonWesley Publishing Company. pp. 216-233. 